\title{
Examination Methods That are Effective in Diagnosing The Primary Origins Of Metastatic Bone Tumors of Unknown Primary Origin During The Initial Visit: A Retrospective Case Series
}

\section{Taketsugu Fujibuchi ( $\boldsymbol{\nabla}$ buchi@m.ehime-u.ac.jp )}

Department of Bone and Joint Surgery, Ehime University Graduate School of Medicine Joji Miyawaki

Department of Bone and Joint Surgery, Ehime University Graduate School of Medicine Teruki Kidani

Department of Bone and Joint Surgery, Ehime University Graduate School of Medicine Hiroshi Imai

Department of Bone and Joint Surgery, Ehime University Graduate School of Medicine Hiromasa Miura

Department of Bone and Joint Surgery, Ehime University Graduate School of Medicine

\section{Research Article}

Keywords: neoplasms, unknown primary, metastasis, bone, diagnosis

Posted Date: December 1st, 2020

DOI: https://doi.org/10.21203/rs.3.rs-112411/v1

License: (a) (i) This work is licensed under a Creative Commons Attribution 4.0 International License. Read Full License 


\section{Abstract}

\section{Background}

The occurrence of skeletal metastases of unknown primary origin (SMUP) is uncommon. To provide appropriate treatments for the primary and metastatic lesions, early diagnosis of the primary origin of SMUP is important. Therefore, this study aimed to assess the types of examination method effective in diagnosing the primary origin of SMUP and their order in terms of efficacy.

\section{Methods}

We retrospectively examined 63 patients with SMUP. The primary origin was examined via physical examination, blood test including tumor markers, chest radiography, thoracoabdominal computed tomography (CT) scan, positron emission tomography (PET)-CT scan, metastatic lesion biopsy, and other assessments. Examination methods considered effective for the diagnosis of the primary origin in a specific type of cancer were investigated.

\section{Results}

The lung was the most common primary origin, followed by the lymph nodes, prostate, and breast. Meanwhile, biopsy (87.0\%) was the most effective examination, followed by PET-CT scan $(60.0 \%)$ and thoracoabdominal CT scan (38.6\%). The first four steps; physical examination, blood tests, chest radiography, thoracoabdominal CT were effective in diagnosing the primary origin in 41 (65\%) of 63 patients. Finally, four patients were diagnosed with SMUP.

\section{Conclusions}

The examination steps used in this study are effective in diagnosing the primary origin of SMUP during the initial visit. Blood tests are useful for hematological malignancy and prostate cancer. CT scan can be used to identify cancers in the lung, breast, and kidney, which are the common primary origins. Moreover, it is more useful than PET-CT scan from a comprehensive perspective.

\section{Background}

It was previously believed that bone metastases indicate terminal-stage cancer. The number of cancer patients has been increasing with greater average life expectancy. The survival rates of various cancers improved with the development of novel therapies. For example, in England, the 1-year survival rate of allstages of lung cancer has improved $\geq 10 \%$ from the 1990 s to the 2010 s due to advancements in diagnosis and treatment[1, 2].Moreover, the treatment of renal cell carcinoma also has significantly progressed in recent years[3]. Approximately $10 \%-15 \%$ of cancers metastasize during clinical course[4]. The lung is the most common metastatic site, followed by the liver and bone[5]. The occurrence of metastatic cancer of unknown primary origin is rare. However, it is still encountered in daily practice. A histologically defined metastatic malignancy in which the primary site cannot be identified after complete 
screening is referred to as cancer of unknown primary (CUP). CUP is one of the major groups of cancer, with an incidence of $3 \%-5 \%$. It is among the ten most common cancers worldwide[6]. The bone is a major site according to the initial presentation of CUP. It accounts for about $36 \%$ of CUP and is the second most frequent site after the lymph nodes[7]. CUP is included in metastatic cancers of unknown primary origin at the first visit. Therefore, the bone is considered a common site of metastatic cancers of unknown primary origin during the initial visit. This condition is referred as skeletal metastases of unknown primary origin (SMUP). A delay in the diagnosis of the primary origin of SMUP during the initial visit can be a problem, since it can inhibit the timely provision of appropriate treatments for the primary and metastatic lesions. Delayed treatment for the primary cancer and skeletal metastasis lead to disease progression and skeletal-related events (SRE), such as pathological fractures, spinal cord compression, or hypercalcemia, respectively. Moreover, it can affect quality of life. Hence, it is important to establish a diagnostic strategy to identify the primary origin and to initiate timely appropriate treatments. When a metastatic bone tumor is suspected, an examination of the primary tumor is performed according to a modified and stylized strategy from a previous literature[8]. Hence, this study aimed to retrospectively assess the types of examination methods effective for diagnosing the primary origin of SMUP during the initial visit and their order in terms of efficacy.

\section{Patients And Methods}

\section{Patients}

A total of 63 patients with SMUP were retrospectively examined during the initial visit between April 2007 and December 2018. However, patients with a previous history of a malignant tumor, those initially suspected with metastatic bone tumor but diagnosed with another disease, and those with another disease but diagnosed with metastatic bone tumor were excluded.

Examination steps for diagnosing the primary origin of cancer

When a metastatic tumor was suspected, the primary origin was examined via physical examination; blood tests, including prostate-specific antigen (PSA), alpha-fetoprotein (AFP), carcinoembryonic antigen, squamous cell carcinoma antigen, soluble interleukin-2 receptor (sIL2-R), and serum protein electrophoresis; chest radiography; thoracoabdominal computed tomography (CT) scan; positron emission tomography (PET)-CT scan; metastatic lesion biopsy; and other assessments. This strategy was a modified version of that reported in a previous literature[8]. Basically, these examinations were discontinued when the primary origin was identified, except when a test was required for further examination and staging of the primary origin.

Data collection and analysis 
Data on age during the initial visit, sex, metastatic sites, examinations performed, examination results, and diagnosis of the primary origin were collected from the clinical records. An examination that could almost diagnose the primary origin was defined as effective. The type of examination effective for the diagnosis of the primary origin was investigated. In addition, the efficacy of each examination including those performed for further evaluation and staging of the primary origin was evaluated.

This retrospective case series was conducted in accordance with the ethical standards described in the Declaration of Helsinki and was approved by the institutional review board of our institution.

\section{Results}

Demographic characteristics of the participants

There were 35 men and 28 women, with a mean age of 68.4 (range, 28-84) years. The thoracic vertebra (85 lesions) was the most common metastatic site, followed by the lumber vertebra (61 lesions) and ribs (49 lesions). Except for the axial skeleton, the ilium (33 lesions) and femur (23 lesions) were also frequent metastatic sites. A total of 19 patients presented with solitary lesions and 44 with multiple lesions (total of 354) (Table 1). The lung ( $n=14)$ was the most common primary site, followed by the lymph nodes: malignant lymphoma $(n=8)$, prostate $(n=8)$, breast $(n=6)$, kidney $(n=5)$, plasma cells: multiple myeloma $(n=5)$, and others (Table 2).

Efficacy of each examination

Biopsy (87.0\%) was the most effective examination, followed by PET-CT scan (60.0\%), and thoracoabdominal CT scan (38.6\%). Physical examination was effective for diagnosing breast cancer. In terms of blood tests, assessment of sIL2-R, immune electrophoresis and PSA were effective for identifying lymphomas, multiple myeloma, and prostate cancer, respectively. Moreover, chest radiography could detect lung cancer. Thoracoabdominal CT scan, PET-CT scan, and biopsy were effective in identifying any types of cancer (Table 3 ).

Number of primary origins identified

Physical examination diagnosed the primary origin in 4 of 63 patients with breast cancer. In 18 of 59 patients, blood test was effective in identifying the primary cancers, which were hematological malignancy and prostate cancer. Then, chest radiography could diagnose the primary origin in 6 of 41 patients, who all had lung cancer. Thoracoabdominal CT scan was effective in detecting the primary origins in 13 of 35 patients ( $n=1$, breast cancer; $n=5$, lung cancer; and $n=3$, liver cancer). In 7 of 22 patients ( $n=2$, gastric cancer, and $n=2$, lung cancer), PET-CT scan could identify the primary origin. Moreover, biopsy was effective in 7 of 15 patients; other methods were used in 4 of 8 patients. The remaining four patients were diagnosed with unknown primary origin (Figure 1).

\section{Discussion}


A diagnostic strategy for identifying the primary origins of SMUP during the initial visit should be established with consideration of various characteristics of examination strategies. The types of examination strategies and their order in terms of efficacy should be determined based on the incidence of a specific type of cancer, extent of invasiveness, and time required for and ability and cost of the method.

In this study, lung cancer was most commonly associated with metastatic bone tumor, followed by malignant lymphoma; prostate, breast, and kidney cancer; and multiple myeloma. In patients with known or unknown primary origin at the time of bone metastasis diagnosis, the breast, lung, prostate, and kidney were the common primary origins $[9,10]$. In patients with SMUP during the initial visit, the common primary origins were the lung, plasma cells, prostate, lymph nodes, kidney, breast, and liver[11, 12]. Whether cancer metastasizes at an early or late stage is based on the type of cancer. However, the lung, breast, prostate, and kidney were the frequent primary origins of skeletal metastases. Myeloma and lymphoma might not be included in the statistics, and hematological cancer was one of the most common primary origins.

The screening methods used differ based on the type of cancer. For lung cancer, low-grade helical CT scan is recommended[13,14]. Mammography is used for the screening of breast cancer, and palpation is included in the diagnostic work-up examinations[15, 16]. Prostate cancer is usually assessed via blood test, including PSA with or without digital rectal examination[16, 17]. Paraprotein and sIL-2 R are important diagnostic markers for myeloma and malignant lymphoma, respectively[18, 19]. In this study, physical examination was useful for the diagnosis of breast cancer, and blood testing was effective for the detection of malignant lymphoma, prostate cancer, and multiple myeloma. Moreover, thoracoabdominal CT scan was effective for the diagnosis of different types of cancer, particularly lung, breast, and liver cancer. PET-CT scan and metastatic lesion biopsy were useful for the identification of most types of cancer. By contrast, the detection rate of chest radiography was $<50 \%$ even in lung cancer. In screening for the primary origin of SMUP, thoracoabdominal CT scans were found to be effective particularly in the diagnosis of patients with lung, hepatocellular, renal cell, and pancreatic carcinomas. Moreover, an elevation serum AFP or PSA level is relatively specific to hepatocellular or prostate carcinoma[12].

Using our strategy modified based on a previous literature[8], physical examination, blood test, chest radiography, and thoracoabdominal CT scan were effective in identifying lesions in 41 (65\%) of 63 patients with SMUP during the initial visit. In a previous report, in approximately $53.3 \%$ of patients, the primary origin of SMUP was diagnosed via common examinations, such as medical history taking, physical examinations, chest radiography, blood test, and whole-body CT scan[11]. The examinations included in the first half of the diagnostic strategy are less invasive and have fewer side effects and are useful for the diagnosis of common primary origins. For example, palpitation for breast cancer, blood test for prostate and hematological cancers, and CT scan for lung and breast cancers are extremely useful examinations. Meanwhile, the efficacy of chest radiography may be limited. However, it was effective in evaluating the patients' general condition. Therefore, if CT scan could be performed quickly, radiography 
might be omitted from this strategy. PET-CT scan was found to be a useful method in identifying the primary origin of SMUP[20,21]. In few cases, PET-CT scan was effective for diagnosis of advanced-stage gastric cancer, which is not detected on CT scan. Furthermore, the diagnostic ability of PET-CT scan $(60.0 \%)$ was higher than that of CT scan (38.6\%). However, CT scan was effective in detecting common primary cancers. That is, in more than $50 \%$ of cases, the primary origins of SMUP were identified during the initial visit via common examinations, including CT scan. In addition, PET-CT scan is more expensive and time-consuming than CT scan. The primary origin of an SMUP could be identified more quickly with the use of CT scan than PET-CT scan[22]. Moreover, CT scan might be more useful than PET-CT scan in detecting the primary origin of SMUP from a comprehensive perspective.

This study had several limitations. First, the number of patients in this study was relatively lower than that in other recent studies. Hence, a statistical analysis was not performed. However, we believe that the results were accurate even though only few patients were included. Next, data on the period from the initial visit to the diagnosis of the primary origin and prognosis of patients with SMUP were not included. The overall survival rate in patients with metastatic bone tumors was correlated with the presence of SRE and spinal metastases, performance status, number of metastases, and primary sites[11, 22]. Moreover, it is challenging to identify a study showing the period between the day of initial visit and date of diagnosis of the primary origin and the relationship between the period required for diagnosis and prognosis. Whether this strategy saves the period required for diagnosing the primary origin of SMUP and whether early diagnosis of the primary origin improves patient prognosis are of great concern. Hence, these issues should be addressed in the future.

\section{Conclusions}

The diagnostic strategies used in this study are effective for the diagnosis of the primary origin of SMUP during the initial visit. That is, $>50 \%$ of patients were diagnosed via blood test, radiography, and thoracoabdominal CT scan. However, radiography can be omitted if CT scan is performed immediately. Blood tests are useful for identifying the common primary origins of SMUP, which include the hematological malignancy and prostate. Moreover, CT scan is useful in identifying lung, breast, and kidney cancers, and it may be more useful than PET-CT scan from a comprehensive perspective. Finally, PET-CT scan is considered effective for the diagnosis of advanced-stage gastric cancer and primary origin not detected on CT scan even though this finding was only observed in few cases.

\section{Abbreviations}

SMUP: skeletal metastases of unknown primary origin; CT: computed tomography; PET: positron emission tomography; CUP: cancer of unknown primary; SRE: skeletal-related events; PSA: prostatespecific antigen; AFP: alpha-fetoprotein; soluble interleukin-2 receptor: sIL2-R

\section{Declarations}




\section{Ethics Approval and consent to participate}

The study was performed in accordance with the ethical standards of the Declaration of Helsinki and was reviewed and approved by Institutional review board (IRB) of Ehime university hospital (No. 1911009). IRB of Ehime University Hospital waived the need for written informed consent from all individual participants due to the retrospective nature of this study.

\section{Consent to publication}

Not applicable

\section{Availability of data and material}

The datasets used and analyzed during the current study are available from the corresponding author on reasonable request.

\section{Competing interests}

The authors declare that they have no competing interests.

\section{Funding}

This research received no specific grant from any funding agency in the public, commercial, or not-forprofit sectors.

\section{Author's contributions}

TF designed this study under professional advices by HI and HM. TF, JM, and TK performed diagnosis, data collection, and analysis. TF was a major contributor in writing the first draft of the manuscript. All authors read and approved the final manuscript.

\section{Acknowledgement}

Not applicable

\section{References}

1. Walters S, Benitez-Majano S, Muller P, Coleman MP, Allemani C, Butler J, et al. Is England closing the international gap in cancer survival? Br J Cancer. 2015;113:848-60.

2. Jones GS, Baldwin DR. Recent advances in the management of lung cancer. Clin Med (Northfield II). 2018;18.

3. Jonasch E, Gao J, Rathmell WK. Renal cell carcinoma. BMJ. 2014;349.

4. Oien KA, Evans TRJ. Raising the profile of cancer of unknown primary. J Clin Oncol. 2008;26:43735. 
5. Biermann JS, Holt GE, Lewis VO, Schwartz HS, Yaszemski MJ. Metastatic bone disease: Diagnosis, evaluation, and treatment. J Bone Jt Surg - Ser A. 2009;91:1518-30.

6. Pavlidis N, Fizazi K. Carcinoma of unknown primary (CUP). Crit Rev Oncol Hematol. 2009;69:271-8. doi:10.1016/j.critrevonc.2008.09.005.

7. Kolling S, Ventre F, Geuna E, Milan M, Pisacane A, Boccaccio C, et al. "Metastatic Cancer of Unknown Primary" or "Primary Metastatic Cancer"? Front Oncol. 2020;9 January.

8. Araki N, Morita T. Clinical Management of Metastatic Bone Disease (in Japanese). 1st edition. Tokyo: KANEHARA \& Co., LTD; 2004.

9. Nottebaert M, Exner GU, von Hochstetter AR, Schreiber A. Metastatic bone disease from occult carcinoma: a profile. Int Orthop. 1989;13:119-23.

10. Zacharia B, Subramaniam D, Joy J. Skeletal Metastasis-an Epidemiological Study. Indian J Surg Oncol. 2018;9:46-51.

11. Takagi T, Katagiri H, Kim Y, Suehara Y, Kubota D, Akaike $K$, et al. Skeletal metastasis of unknown primary origin at the initial visit: A retrospective analysis of 286 cases. PLoS One. 2015;10:1-17.

12. Katagiri $H$, Takahashi $M$, Inagaki J, Sugiura $H$, Ito $S$, Iwata $H$. Determining the site of the primary cancer in patients with skeletal metastasis of unknown origin: A retrospective study. Cancer. 1999;86:533-7.

13. Oudkerk M, Devaraj A, Vliegenthart R, Henzler T, Prosch H, Heussel CP, et al. European position statement on lung cancer screening. Lancet Oncol. 2017;18:e754-66. doi:10.1016/S14702045(17)30861-6.

14. Hoffman RM, Sanchez R. Lung Cancer Screening. Med Clin North Am. 2017;101:769-85. doi:10.1016/j.mcna.2017.03.008.

15. Cardoso F, Kyriakides S, Ohno S, Penault-Llorca F, Poortmans P, Rubio IT, et al. Early breast cancer: ESMO Clinical Practice Guidelines for diagnosis, treatment and follow-up. Ann Oncol. 2019;30:1194220. doi:10.1093/annonc/mdz173.

16. Smith RA, Andrews KS, Brooks D, Fedewa SA, Manassaram-Baptiste D, Saslow D, et al. Cancer screening in the United States, 2017: A review of current American Cancer Society guidelines and current issues in cancer screening. CA Cancer J Clin. 2017;67:100-21.

17. Heijnsdijk EAM, Bangma CH, Borràs JM, de Carvalho TM, Castells X, Eklund M, et al. Summary statement on screening for prostate cancer in Europe. Int J Cancer. 2018;142:741-6.

18. Mehta A. Multiple myeloma. Hematology. 2015;20:58-9.

19. Yoshida N, Oda M, Kuroda Y, Katayama Y, Okikawa Y, Masunari T, et al. Clinical significance of sIL-2R levels in B-cell lymphomas. PLoS One. 2013;8:1-10.

20. Tamam C, Tamam M, Mulazimoglu M. The accuracy of $18 \mathrm{~F}-$ Fluorodeoxyglucose positron emission tomography/computed tomography in the evaluation of bone lesions of undetermined origin. World J Nucl Med. 2016;15:124. 
21. Park S Bin, Park JM, Moon SH, Cho YS, Sun JM, Kim BT, et al. Role of18F-FDG PET/CT in patients without known primary malignancy with skeletal lesions suspicious for cancer metastasis. PLoS One. 2018;13:1-11.

22. Shimada H, Sethoguchi T, Yokouchi M, Hiromi S, Ishodou Y, Kawamura I, et al. Metastatic bone tumors: Analysis of factors affecting prognosis and efficacy of CT and 18F-FDG PET-CT in identifying primary lesions. Mol Clin Oncol. 2014;2:875-81.

\section{Tables}

Table 1 Site of metastatic lesions 
Solitary metastasis $(n=19)$

Site of metastasis Number of patients

Cervical vertebra 1

Cervical vertebra $2 \quad 1$

Cervical vertebra 3

Cervical vertebra 4

Cervical vertebra 5

Cervical vertebra 6

Cervical vertebra 7

Thoracic vertebra 1

Thoracic vertebra

2

Thoracic vertebra 3

Thoracic vertebra 4

Thoracic vertebra 5

Thoracic vertebra 6

Thoracic vertebra 7

Thoracic vertebra 8

Thoracic vertebra 9

Thoracic vertebra 1 10

Thoracic vertebra 11

Thoracic vertebra 2 12

Lumbar vertebra 1

Lumbar vertebra 2
Multiple metastasis (354 lesions in 44 patients)

Site of metastasis Number of patients

Cervical vertebra 11

Cervical vertebra $2 \quad 5$

Cervical vertebra $3 \quad 1$

Cervical vertebra $4 \quad 3$

Cervical vertebra $5 \quad 5$

Total: Cervical vertebra 64

1 Cervical vertebra 74

Total:

23

Thoracic vertebra 4

1

Thoracic vertebra 5

2

Thoracic vertebra 5

3

Thoracic vertebra 6

4

Thoracic vertebra $\quad 10$

5

Thoracic vertebra 4

6

Thoracic vertebra 6

7

Thoracic vertebra 4

8

Thoracic vertebra 12

9

Thoracic vertebra $\quad 10$

10

Total: Thoracic vertebra 9

Total: 11

$3 \quad$ Thoracic vertebra 7

12

82
Lumbar vertebra $1 \quad 10$

Lumbar vertebra $2 \quad 9$ 


\begin{tabular}{|c|c|c|c|c|c|}
\hline \multicolumn{3}{|l|}{ Lumbar vertebra 3} & \multirow{2}{*}{$\begin{array}{l}\text { Lumbar vertebra } 3 \\
\text { Lumbar vertebra } 4\end{array}$} & \multicolumn{2}{|l|}{11} \\
\hline Lumbar vertebra 4 & 2 & Total: & & 15 & Total: \\
\hline Lumbar vertebra 5 & & 4 & Lumbar vertebra 5 & 12 & 57 \\
\hline Sacral vertebra 1 & 1 & & Sacral vertebra 1 & 16 & \\
\hline Sacral vertebra 2 & & & Sacral vertebra 2 & 8 & \\
\hline Sacral vertebra 3 & & & Sacral vertebra 3 & 4 & \\
\hline Sacral vertebra 4 & & Total: & Sacral vertebra 4 & 2 & Total: \\
\hline Sacral vertebra 5 & & 1 & Sacral vertebra 5 & 1 & 31 \\
\hline Rib 1 & & & Rib 1 & 4 & \\
\hline Rib 2 & & & Rib 2 & 2 & \\
\hline Rib 3 & & & Rib 3 & 3 & \\
\hline Rib 4 & & & Rib 4 & 2 & \\
\hline Rib 5 & & & Rib 5 & 6 & \\
\hline Rib 6 & & & Rib 6 & 7 & \\
\hline Rib 7 & & & Rib 7 & 6 & \\
\hline Rib 8 & & & Rib 8 & 4 & \\
\hline Rib 9 & 1 & & Rib 9 & 8 & \\
\hline Rib 10 & & & Rib 10 & 4 & \\
\hline Rib 11 & & Total: & Rib 11 & 1 & Total: \\
\hline Rib 12 & & 1 & Rib 12 & 1 & 48 \\
\hline Cranium & & & Cranium & 2 & \\
\hline Clavicula & 1 & & Clavicula & 1 & \\
\hline Scapula & 2 & & Scapula & 11 & \\
\hline Sternum & & & Sternum & 4 & \\
\hline Humerus & 1 & & Humerus & 9 & \\
\hline Ilium & 2 & & Ilium & 31 & \\
\hline Pubis & & & Pubis & 17 & \\
\hline Ischium & & & Ischium & 16 & \\
\hline Femur & 3 & & Femur & 20 & \\
\hline
\end{tabular}


Table 2 Primary origin of skeletal metastasis of unknown primary origin

\begin{tabular}{|ll|}
\hline Primary cancer & Number of patients (\%) \\
\hline Lung cancer & $14(22.2)$ \\
\hline Malignant lymphoma & $8(12.7)$ \\
\hline Prostate cancer & $7(11.1)$ \\
\hline Breast cancer & $6(9.5)$ \\
\hline Kidney cancer & $5(7.9)$ \\
\hline Multiple myeloma & $5(7.9)$ \\
\hline Liver cancer & $4(6.3)$ \\
\hline Thyroid cancer & $3(4.8)$ \\
\hline Stomach cancer & $2(3.2)$ \\
\hline Uterus cancer & $2(3.2)$ \\
\hline Urinary bladder cancer & $1(1.6)$ \\
\hline Ovary cancer & $1(1.6)$ \\
\hline Anal canal cancer & $1(1.6)$ \\
\hline Unknown & $4(6.3)$ \\
\hline
\end{tabular}

Table 3 Efficacy of each examination according to primary cancer 


\begin{tabular}{|c|c|c|c|c|c|c|}
\hline $\begin{array}{l}\text { Primary } \\
\text { lesion }\end{array}$ & $\begin{array}{l}\text { Physical } \\
\text { examination }\end{array}$ & $\begin{array}{l}\text { Blood } \\
\text { test }\end{array}$ & $\begin{array}{l}\text { Chest } \\
\text { radiography }\end{array}$ & $\begin{array}{l}\text { Thoracoabdominal } \\
\text { CT scan }\end{array}$ & $\begin{array}{l}\text { PET-CT } \\
\text { scan }\end{array}$ & Biopsy \\
\hline \multirow[t]{2}{*}{ Total } & $4 / 63$ & $18 / 63$ & $6 / 63$ & $22 / 47$ & $18 / 30$ & $19 / 22$ \\
\hline & $(6.3 \%)$ & $(28.6 \%)$ & $(9.5 \%)$ & $(38.6 \%)$ & $(60.0 \%)$ & (87.0\%) \\
\hline Lung cancer & $0 / 14$ & $0 / 14$ & $6 / 14$ & $6 / 10$ & $6 / 6$ & $4 / 4$ \\
\hline $\begin{array}{l}\text { Malignant } \\
\text { lymphoma }\end{array}$ & $0 / 8$ & $6 / 8$ & $0 / 8$ & $1 / 4$ & $0 / 5$ & $4 / 5$ \\
\hline $\begin{array}{l}\text { Prostate } \\
\text { cancer }\end{array}$ & $0 / 7$ & $7 / 7$ & $0 / 7$ & $3 / 6$ & $1 / 1$ & $0 / 0$ \\
\hline $\begin{array}{l}\text { Breast } \\
\text { cancer }\end{array}$ & $4 / 6$ & $0 / 6$ & $0 / 6$ & $5 / 6$ & $3 / 5$ & $1 / 1$ \\
\hline $\begin{array}{l}\text { Kidney } \\
\text { cancer }\end{array}$ & $0 / 5$ & $0 / 5$ & $0 / 5$ & $2 / 5$ & $2 / 2$ & $4 / 4$ \\
\hline $\begin{array}{l}\text { Multiple } \\
\text { myeloma }\end{array}$ & $0 / 5$ & $5 / 5$ & $0 / 5$ & $0 / 4$ & $0 / 0$ & $0 / 0$ \\
\hline Liver cancer & $0 / 4$ & $0 / 4$ & $0 / 4$ & $3 / 4$ & $0 / 0$ & $2 / 2$ \\
\hline $\begin{array}{l}\text { Thyroid } \\
\text { cancer }\end{array}$ & $0 / 3$ & $0 / 3$ & $0 / 3$ & $0 / 1$ & $2 / 2$ & $3 / 3$ \\
\hline $\begin{array}{l}\text { Stomach } \\
\text { cancer }\end{array}$ & $0 / 2$ & $0 / 2$ & $0 / 2$ & $0 / 2$ & $2 / 2$ & $0 / 0$ \\
\hline $\begin{array}{l}\text { Uterus } \\
\text { cancer }\end{array}$ & $0 / 2$ & $0 / 2$ & $0 / 2$ & $1 / 2$ & $2 / 2$ & $0 / 0$ \\
\hline $\begin{array}{l}\text { Urinary } \\
\text { bladder } \\
\text { cancer }\end{array}$ & $0 / 1$ & $0 / 1$ & $0 / 1$ & $0 / 0$ & $0 / 1$ & $1 / 1$ \\
\hline $\begin{array}{l}\text { Ovary } \\
\text { cancer }\end{array}$ & $0 / 1$ & $0 / 1$ & $0 / 1$ & $1 / 1$ & $0 / 0$ & $0 / 0$ \\
\hline $\begin{array}{l}\text { Anal canal } \\
\text { cancer }\end{array}$ & $0 / 1$ & $0 / 1$ & $0 / 1$ & $0 / 0$ & $0 / 1$ & $0 / 0$ \\
\hline Unknown & $0 / 4$ & $0 / 4$ & $0 / 4$ & $0 / 2$ & $0 / 3$ & $0 / 2$ \\
\hline
\end{tabular}

Each column shows the number of patients who were accurately diagnosed and number of examinations

\section{Figures}




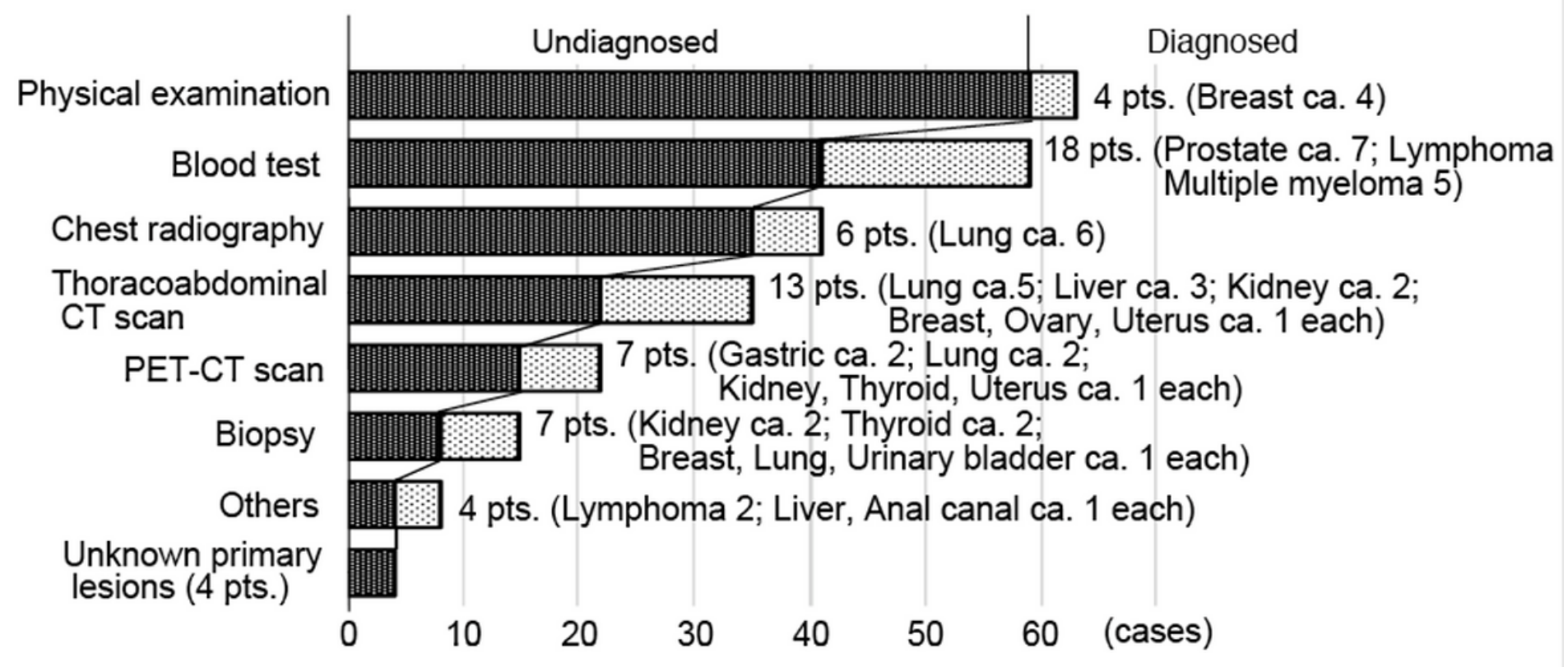

\section{Figure 1}

Number of identified primary lesions using the diagnostic methods Examinations of each steps are set on the axis of ordinate while the number of primary origins identified is set on the axis of abscissa. The first four steps; physical examination, blood tests, chest radiography, thoracoabdominal CT were effective in diagnosing the primary origin in $41(65 \%)$ of 63 patients.

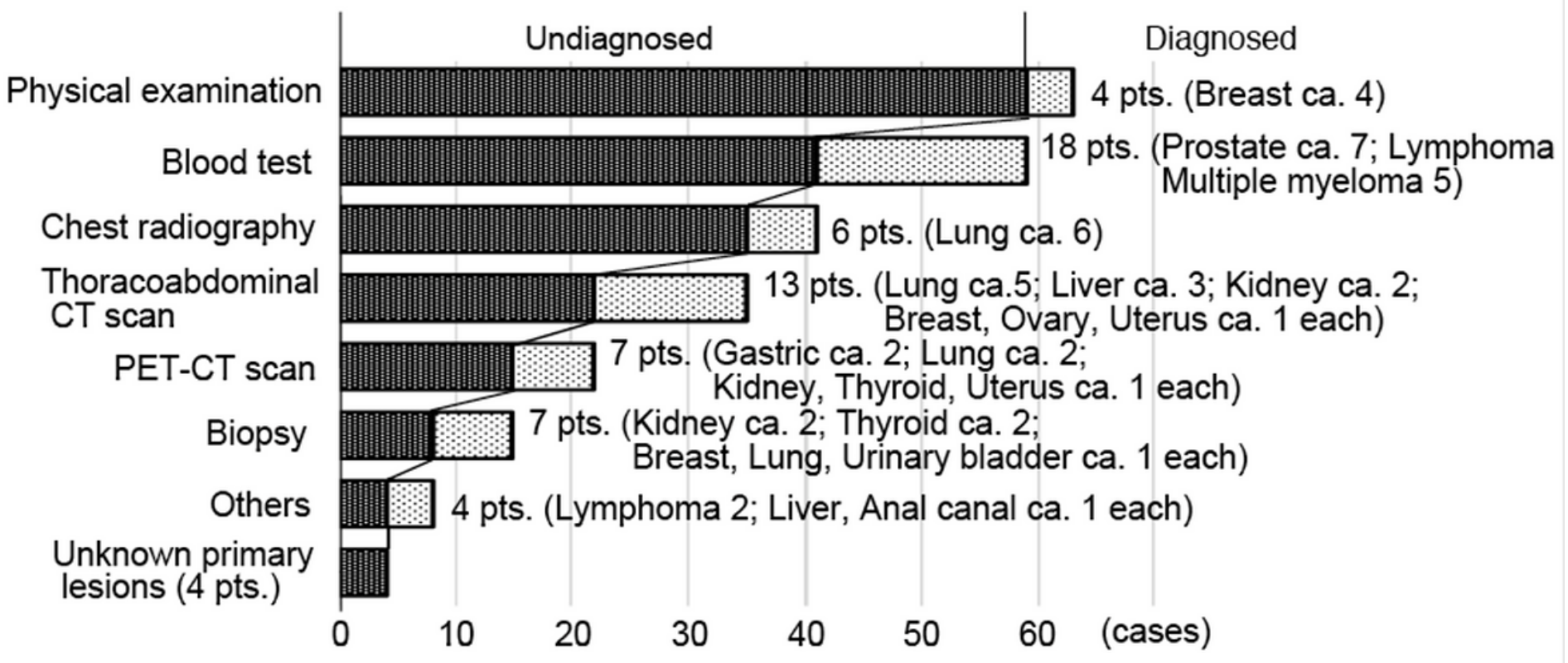

Figure 1

Number of identified primary lesions using the diagnostic methods Examinations of each steps are set on the axis of ordinate while the number of primary origins identified is set on the axis of abscissa. The first 
four steps; physical examination, blood tests, chest radiography, thoracoabdominal CT were effective in diagnosing the primary origin in $41(65 \%)$ of 63 patients. 